\title{
Are Innovative Events Help to Build Brand Image? A Study on The Daily Prothom Alo Regarding Mathematical Olympiad
}

\author{
Sayaka Zaman* \\ Department of Business Studies, State University of Bangladesh, Sobhan Tower, 138, Kalabagan, Mirpur Road \\ Dhaka -1205
}

\begin{abstract}
The following abstract is highlighting the study titled "Are innovative events help to build brand image? "The daily Prothom Alo is a leading Bengali newspaper with highest readership in the country. It has a 'numbered' of publications each day which is highest among other 'number' of publications in the country. For the past 17 years, Daily Prothom Alo has been organizing mathematical Olympiad for students all over the 64 districts of Bangladesh. At initial stages, a total of 50 thousands of students register all over the country. After a round of selection process, top students who qualify at final round, got a chance to participate in international stages. And there are instances of students after participating, qualify for scholarship for higher studies. The following study tried to elaborate the total programmed flow in light of marketing theories and try to establish a strong connection between the organized events with building a strong brand image. The effect of this particular event giving competitive advantages to Prothom Alo by creating positive impact among current readership, creating new readership among young students, build a strong brand image of being an enabler for a better future. We also try to establish a tangible benefit for Prothom Alo in reflecting on quality management, ROI etc. From both scholastic and practical perspective this research is significant as it has deliberately investigations the components which work for making brand image and competitive advantage, which can be used by different organizations to accomplish "Sustainable Brand Quality" and furthermore the research paper can be utilized as lead for others to think about further in this issue.

Keywords: Brand awareness, Event marketing, Brand image, Brand \& customer loyalty,

DOI: $10.7176 / \mathrm{EJBM} / 12-27-03$
\end{abstract}

Publication date:September $30^{\text {th }} 2020$

\section{Introduction}

There is no alternative to marketing to survive and improve in the current competitive world of business. A successful marketing process of a company plays a vital role in creating an unbeatable position in the market over competitor companies. In addition to direct marketing through commercials, successful event marketing can also play an important role in the company's success. The Daily Prothom Alo and the Dutch-Bangla Bank's initiative, organized by the Bangladesh Mathematical Olympiad Committee, Bangladesh Mathematical Olympiad is working as a great event marketing tool for both of the companies. The 17-year old Math Olympiad is supporting in marketing through reputation building, loyal customer building, higher recall value, word of mouth marketing, healthy competition, and higher sales value. It is well-evaluated in the post-event survey.

\section{Purpose and Research Significances:}

This paper goes for examining and breaking down The Daily Prothom Alo's procedures and overall techniques of crafting brand image and keeps up ISO standard quality so as to see how The Daily Prothom Alo has accomplished competitive advantage and keeping pace with changes. This paper also will reflect on quality management related topics, specially the aspects of profitability (ROI) and competitive advantage resulting from events management.

From both scholastic and practical perspective this research is significant as it has deliberately investigations the components which work for making brand image and competitive advantage, which can be used by different organizations to accomplish "Sustainable Brand Quality" and furthermore the research paper can be utilized as lead for others to think about further in this issue.

\section{Methodology}

This paper is entirely based on secondary information and researcher will try to use an empirical case study approach to describe the brand image efforts made and planned by a business organization. In this case, it will be The Daily Prothom Alo (a leading print media currently operating in Bangladesh). The study is based on theories on brand quality management to gain competitive advantage. Following the theoretical discussion, the paper presents the empiricism on the company's event management efforts to get competitive advantage in terms of thinking, strategies and practices. This empirical study is followed by an analysis based upon the theories to have an insight to their brand image creating efforts for competitive advantage and tries to find areas for further improvement. 


\section{Bangladesh Mathematical Olympiad as an event:}

Bangladesh Mathematical Olympiad is one of the largest and successful events of Bangladesh that ensures participation of around 50 thousand school and college students (Class 3- Class 12).Participation of 50 thousand students implies an engagement of 50 thousand families.

The Daily Prothom Alo (the leading newspaper of Bangladesh) manages the event. Prothom Alo runs hundreds of marketing programs every year, but the Mathematical Olympiad becomes the most influential event marketing platform of the newspaper. It confirms a face-to-face interaction between Prothom Alo and its readers.

Bangladesh Mathematical Olympiad is not limited to a traditional educational program. It becomes a festival that includes cultural programs, bicycle stunt, puppet show, Rubik's cube contest, book fair, food fair and many more to ensure a pleasant people engagement while they are in a willing and participatory mood.

\subsection{Background of Bangladesh Mathematical Olympiad}

Bangladesh Mathematical Olympiad started its journey in April 2001. The program is organized by Bangladesh Mathematical Olympiad Committee, sponsored by Dutch-Bangla Bank Ltd and managed by The Daily Prothom Alo. This yearly event is open for all school and college students (up to class 12) of Bangladesh. This initiative has introduced a joyful Mathematics practice all over the country.

Bangladesh team has been participating in the International Mathematical Olympiad (IMO) since 2005. In the meantime, Bangladesh secured 1 Gold, 6 Silver, 22 Bronze medals and 27 Honorable mentions from there.

\subsection{Participation:}

School and College students (from class 3 to class 12) from all districts of Bangladesh participate in this program. All students are grouped into four groups. These are Primary (from class 3 to class 5), Junior (from class 6 to class 8), Secondary (from class 9 to class 10) and Higher Secondary (from class 11 to class 12).

There are three rounds for the selection process. These are Selection round, Regional round, and National round. Selection round is the beginning of this process. Around 50 thousand students take part in the examination by a pre-registration process. From the Selection round, 14 thousand students participate in the second round (Regional round). From 12 Regional rounds, top 1400 student get the chance to participate in the final National round. Finally, around 85 top students get the opportunity to attend the camps from where top 6 students participate in International Mathematical Olympiad (IMO).

\subsection{Preparation and Execution:}

After the confirmation of the budget from the sponsors, academic volunteers set questions for the selection round. In the meantime, logistics volunteers ensure different logistic supports. Local representatives confirm student registration and book exam venues. Around 3500 volunteers are engaged behind the success of this event. Again, academic volunteers check the answer sheets and prepare results. Qualified students get SMS and phone call for the next round participation. Announcements have been published in newspaper advertisements, Bangladesh Mathematical Olympiad website, and Facebook page.

\subsection{Certification and Rewards:}

All selected students from each round receive certificates. In the final round (National round), students receive certificates, medals, T-shirts, crests and cash money.

\subsection{Marketing through Bangladesh Mathematical Olympiad}

Bangladesh Mathematical Olympiad is one of the most successful event marketing programs of Prothom Alo. It plays a vital role in making Prothom Alo the most influential brand in Bangladesh. The event has successfully been accomplishing for the last 17 years. It has a high positive recall value and a long-term sustainable positive brand value of the company.

\subsection{Performance in International Mathematical Olympiad (IMO)}

Mathematical Olympiad has started a joyful practice of Mathematics in Bangladesh. Nowadays, students find Mathematics as an interesting subject. A positive reflection has been seen in International Mathematical Olympiad (IMO) score with a continuous growth since its inception. 


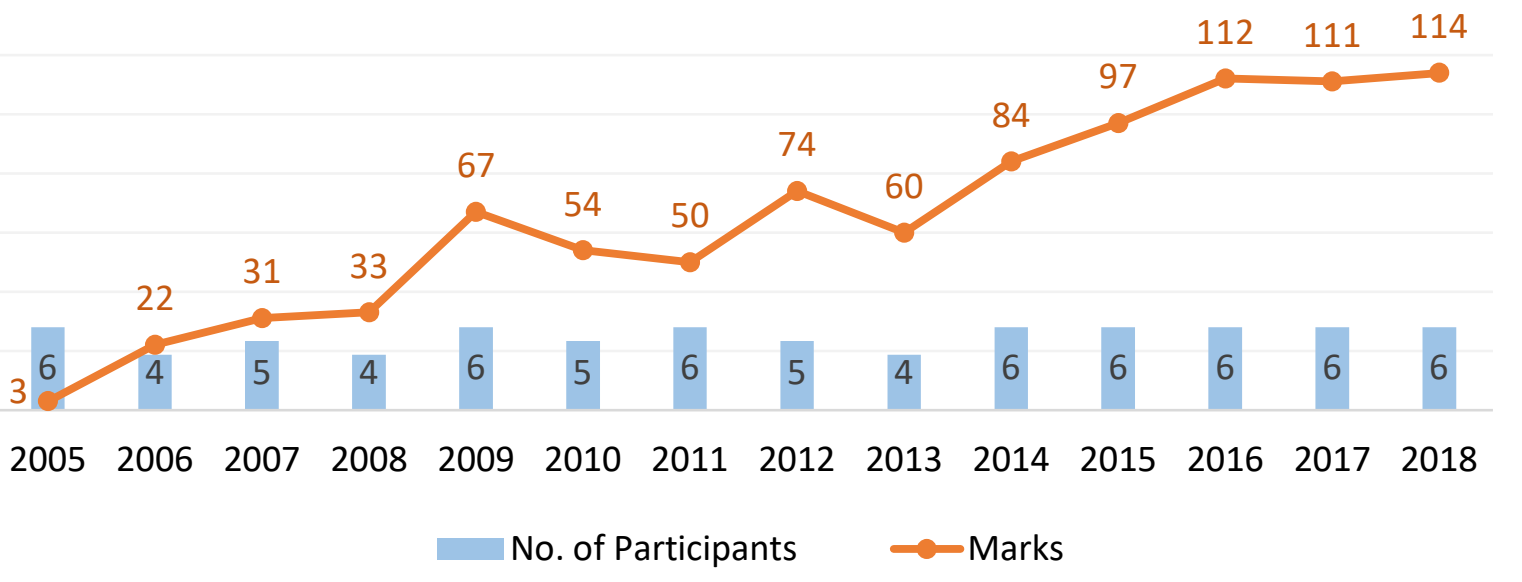

Source: https://www.imo-official.org/country_team_r.aspx?code=BGD\&column=year\&order=desc

\subsection{Achievements in International Mathematical Olympiad (IMO)}

Bangladesh team's performance in International Mathematical Olympiad is highly appreciable. It works like a lifechanging event for Bangladeshi participants. Many local and international recognitions and fully-funded scholarships from the world's top universities have changed their lives and opened the doors of opportunities in front of them. A glimpse is given below:

\begin{tabular}{|c|c|c|c|}
\hline Year & Contestant & Medals & University \\
\hline 2018 & Ahmed Zawad Chowdhury & Gold & Massachusetts Institute of Technology (MIT) \\
\hline 2018 & Tamzid Morshed Rubab & Bronze & Waiting for admission \\
\hline 2018 & Joydip Saha & Bronze & Waiting for admission \\
\hline 2018 & ThanicNurSamin & Bronze & Waiting for admission \\
\hline 2017 & Ahmed Zawad Chowdhury & Silver & Massachusetts Institute of Technology (MIT) \\
\hline 2017 & Asif E Elahi & Silver & University of Cambridge \\
\hline 2017 & Tamzid Morshed Rubab & Bronze & Waiting for admission \\
\hline 2017 & Rahul Saha & Bronze & Princeton University \\
\hline 2016 & Ahmed Zawad Chowdhury & Bronze & Massachusetts Institute of Technology (MIT) \\
\hline 2016 & Asif E Elahi & Silver & University of Cambridge \\
\hline 2016 & Md Sabbir Rahman & Bronze & Massachusetts Institute of Technology (MIT) \\
\hline 2016 & Sazid Akhter Turzo & Bronze & University of Cambridge \\
\hline 2015 & Md Sanzeed Anwar & Silver & Massachusetts Institute of Technology (MIT) \\
\hline 2015 & Asif E Elahi & Bronze & University of Cambridge \\
\hline 2015 & Adib Hasan & Bronze & Massachusetts Institute of Technology (MIT) \\
\hline 2015 & Md Sabbir Rahman & Bronze & Massachusetts Institute of Technology (MIT) \\
\hline 2015 & Sazid Akhter Turzo & Bronze & University of Cambridge \\
\hline 2014 & Adib Hasan & Bronze & Massachusetts Institute of Technology (MIT) \\
\hline 2014 & Nur Muhammad Shafiullah & Silver & Massachusetts Institute of Technology (MIT) \\
\hline 2013 & Sourav Das & Bronze & Massachusetts Institute of Technology (MIT) \\
\hline 2013 & Adib Hasan & Bronze & Massachusetts Institute of Technology (MIT) \\
\hline 2013 & Nur Muhammad Shafiullah & Bronze & Massachusetts Institute of Technology (MIT) \\
\hline 2012 & Dhananjoy Biswas & Silver & Shahjalal University of Science \& Technology \\
\hline 2012 & Sourav Das & Bronze & Massachusetts Institute of Technology (MIT) \\
\hline 2012 & Nur Muhammad Shafiullah & Bronze & Massachusetts Institute of Technology (MIT) \\
\hline 2011 & Dhananjoy Biswas & Bronze & Shahjalal University of Science \& Technology \\
\hline 2010 & Tarik Adnan Moon & Bronze & Harvard University \\
\hline 2009 & NaziaNaser Chowdhury & Bronze & $\begin{array}{l}\text { Massachusetts Institute of Technology (MIT), } \\
\text { National University of Singapore }\end{array}$ \\
\hline 2009 & SaminRiasat & Bronze & $\begin{array}{l}\text { University of } \\
\text { University of Waterloo }\end{array}$ \\
\hline
\end{tabular}

Source: https://www.imo-official.org/country_individual_r.aspx?code=BGD\&column=name\&order=desc 


\section{Theoretical Foundations:}

\subsection{Event Marketing:}

Event marketing is a marketing strategy that involves direct interaction (face-to-face) between companies and their customers or clients at special events. This practice ensures consumer engagement and creates opportunities to have opinions and feedbacks from customers. By identifying a target group of audience correctly, a successful event marketing can create a positive impression towards a company and make a long-lasting relationship with consumers. Event marketing can create a buzz so that customers can recall the memories long after the event is over. It makes a plot for a positive branding through words of mouth.

Beyond the typical advertising with millions of general consumers through television, radio or billboard advertisements, event marketing targets particular individuals or groups at a gathering spot for making quality individual impressions and interactions.

\subsection{Brand Image}

This event, Mathematical Olympiad, has been running successfully since 2001. Every year it creates a buzz among the youngsters. There are many students who start their participation from class 3 and continue till class 12 . Even they engage themselves with this event after their participation as a mentor or well-wisher. In fact, yearly repetition of the event, extensive print and digital coverage, participation, word of mouth discussion, prestigious fully-funded scholarships of the winner from the world recognized universities have made this event as an unforgettable event of every participant's life. This implies a positive impression on the brand Prothom Alo.

Mass people identify this event as a Prothom Alo program. And, they appreciate this event a lot since Prothom Alo has been arranging this event beyond the typical role of a newspaper. The voluntary work of Mathematical Olympiad is well recognized by local companies as a strong extracurricular activity.

Mathematical Olympiad has influenced the government as well. This event applies a joyful Math practice for the students. To eradicate the fears of Math, the Bangladesh government has started a project of learning Math by Mathematical Olympiad method. This indicates the acceptance of Mathematical Olympiad all over the county.

\subsection{Customer Loyalty}

In the present focused business field it's expensive to draw in new client than to hold existing client, so continuing existing clients steadfast is an essential issue for the administration arranged organizations uncommonly media transmission enterprises. Organizations who are looking for steadfast client ought to accentuate on consumer loyalty (Yang and Peterson, 2004). Consumer loyalty isn't just the direct deciding element of client unwaveringness yet in addition the focal determinant of client maintenance (Gerpott et al., 2001). Cooil et al. (2007) has seen that client devotion is a significant key target. Some specialist (Gould, 1995; Kotler, 1998; Reichheld, 2001) speaks to their perspectives that extension, protection, and boosting of client dependability imply a focal promoting procedure for accomplishing upper hand.

Sirdeshmukh et al. (2002) portrayed the significance of significant worth in the faithfulness and relationship building and support in the more extended term by delineating that clients utilized the incentive to accomplish higher objectives through connections since they can't assess the innovation itself since this procedure appears to be very hard for them. They may just see the innovation change.

Yang and Peterson (2004) states client dedication is a unique credit of client frame of mind to proceed with an association with a specialist organization. As indicated by Oliver (1999, p 34) devotion is "a profoundly held responsibility to re-purchase or re-belittle a favored item/administration reliably later on". To keep up relationship long haul client reliability assumes a crucial job. It is clear long haul client unwaveringness bring positive outcome for specialist co-op and help them to manufacture solid association with client and hold existing clients. Quality clients bolster improving client faithfulness as well as make long length connection among clients and specialist co-ops.

\subsection{Relationship Marketing}

Relationship promoting is a consistent procedure for investigating new an incentive inside individual clients and after that dispersing the advantages over a lifetime relationship (Gordon, I. 1998). Relationship advertising comprises of in a chain of relationship which involve everybody from providers, representatives, clients, financial specialists and the governing body, including dispersion channels and others. At last, expanding esteem utilized is at last clients (Gordon, 1998). Relationship promoting more stress on relationship, systems administration and communication.

Gronroos (2000) has been characterized Relationship Marketing (RM) is 'The way toward distinguishing and building up, keeping up, improving and when vital ending association with clients and others partners, at a benefit, so target of all gatherings included are met, where this is finished by shared giving and satisfaction of guarantees.' Organizations trust that they give precisely what clients want from their administration experience and recognitions. The reason for an administration is to make commonly useful relationship (Paulin, 2000). 
Each business contains relationship by trading their item or administration. Fruitful business association stipulates on make and deal with a complete administration offering in a client situated framework. Consumer loyalty and long haul relationship additionally rely upon the client anticipated administration (Zeithaml, 2003). As indicated by Gronroos (2007) trust, duty and fascination most significant job for relationship advertising and well client driven administration framework created by four focal assets: Employees, innovation, client and time.

As per Tohidinia and Haghighi (2011), relationship showcasing can help the specialist organizations in building up stable associations with customers by the methods for expanding advertising productivity, diminished proportion of client abandonment and arrangement of client wants and needs which can build the consumer loyalty and faithfulness.

\section{Empirical Study and Analysis: 6.1 Reputation Building:}

Bangladesh Mathematical Olympiad has undoubtedly brought a solid reputation for Prothom Alo. The continuous arrangement of the event has made a loyal reader base for the newspaper. Moreover, there are many former participants who are still engaged with the program for last many years. The giant event has made a buzz countrywide. The opportunity to get international recognition and full funded scholarship from the world's best universities through Bangladesh Mathematical Olympiad helps the company to draw an immense attention of quality target group of people.

\subsection{Building Loyal Reader:}

Generally, Bangladesh Mathematical Olympiad participants become regular readers of Prothom Alo. The early participants are still loyal readers of Prothom Alo. They also engage themselves with different activities of Prothom Alo. Moreover, the present school and college students have a positive impression on Prothom Alo.

\subsection{Higher Recall Value:}

The program has been continuing for the last 17 years. Moreover, the selection round, the regional round, the national round, camps, and finally IMO participation make a year-long engagement with the participants in every year. Print and digital advertisements, news articles, social media posts, and overall event coverage confirm a noteworthy mass communication with different types of people.

\subsection{Word of Mouth Marketing:}

Any verbal or written recommendation by a satisfied customer to the prospective customers of a good or service is called Word of Mouth Marketing. The previous success stories of Bangladesh Mathematical Olympiad have set examples for the present students. Nowadays, parents encourage their offspring to participate in the Bangladesh Mathematical Olympiad. It becomes a topic of discussion in many gatherings. As a result, it is considered as one of the most effective Word of Mouth Marketing tools for the company.

\subsection{Healthy Competition:}

Almost all companies in the globe are passing through a competing market situation. Different companies launch different types of marketing strategies to survive in the market and win the race. In Bangladesh, many newspapers organize a number of events to establish a strong position in the market. But an event like Bangladesh Mathematical Olympiad undoubtedly places Prothom Alo one step forward than any other competitor event.

\subsection{Higher Sales:}

Bangladesh Mathematical Olympiad increases Prothom Alo sales. During the days of any announcement and event coverage, Prothom Alo sales get an extra boost since many irregular readers/students collect the newspaper for that particular issue. Even a notable number of Prothom Alo copies are sold at the event spot since the spot is entry restricted and there are many awaiting guardians outside the exam halls.

\subsection{Evaluation:}

A post-event survey showed that if Bangladesh Mathematical Olympiad participants are asked what come to their mind after hearing about MATH OLYMPIAD, they can recall the name PROTHOM ALO in the 2nd position visà-vis if Prothom Alo readers are asked about PROTHOM ALO, they can recall the Bangladesh Mathematical Olympiad in the 5 th position.

\subsection{Considerations:}

Though event marketing is highly essential for a successful business, it is truly time consuming and expensive. Planning, budget making, sponsoring, logistics, mailing, advertising, venue confirmation, catering, volunteer management, media coverage, guest management, and academic support require a huge budget and managerial 
expertise. Gathering the right target group of people with proper demography is always a big challenge. Moreover, it requires an enormous effort to manage the primary set-up. Therefore, it is very tough to run event marketing for small and medium-sized enterprises.

\subsection{Return on Investment (ROI) of the Event}

It is a crucial step to measure the ROI of an event. There are intangible and tangible values to measure for it. Of course, tangible event ROI can be measured by the number of tickets sold or registration, revenue earning, creating new opportunities, strengthening the existing business relationship and so on. But there are other equally important intangible elements that should be considered to measure the event success.

\subsubsection{Tangible Value}

\subsubsection{Registration:}

Registration is a significant sign of tangible ROI. The number of registration of Bangladesh Mathematical Olympiad is increasing day-by-day. Around 50,000 students participated in this year's event with proper registration. This is a tangible reflection of the event success.

\subsubsection{Expenditures:}

Bangladesh Mathematical Olympiad is basically a non-profit initiative of Prothom Alo. And, the registration is completely free for students. The main objective of this event is to ensure an enormous student involvement with this program. After all, the event is successfully done within the budget from the sponsor.

\subsubsection{Loyal Participants:}

Bangladesh Mathematical Olympiad has created a loyal group of participants for Prothom Alo. It is commonly found that Mathematical Olympiad's participants take part in other programs of Prothom Alo. So, this event influences Prothom Alo's other events to be successful.

\subsubsection{Stronger Business Relationship and New Opportunities:}

After the success of this event, a solid base of business relationship has created between Prothom Alo and DutchBangla Bank Limited. Now, Dutch-Bangla Bank shows interest to sponsor other programs of Prothom Alo. Moreover, Dutch-Bangla Bank inserts more advertisements in Prothom Alo than before.

\subsubsection{Intangible Value \\ 6.9.2.1 Operational Excellence:}

"Event planners must account for all details and contingency plans and more contingency plans, depending on the size and complexity of a program," says Nicholas Chan, production manager at Convene. "How we manage the communication between the internal team and our clients ultimately proves how adept we are at navigating through changes and sometimes tricky situations."

The entire process of Bangladesh Mathematical Olympiad goes through a disciplined way. From the initial planning stage to the final International Mathematical Olympiad participation, everything is done by a group of trained and expert people. As a result, the efficient process leads to cost and time saving excellent operation.

\subsubsection{Brand Awareness:}

The name Prothom Alo is extremely involved with Bangladesh Mathematical Olympiad. Print and digital advertisements, news and features, social posts, social shares and general word of mouth create amazing intangible benefits for Prothom Alo by this event. An extraordinary response from the students and targeted audience boost the chance of securing sponsorships for future events as well.

\subsubsection{Participant Satisfaction:}

A post-event survey has been done immediately after the end of the event to evaluate the success of Bangladesh Mathematical Olympiad and collect data for improving the next events. The proportion of highly satisfied attendees is increasing every year.

\section{Findings}

Bangladesh Mathematical Olympiad is a great event marketing tool for both Prothom Alo and Dutch-Bangla Bank Limited. This Olympiad helps the companies to draw immense attention to the quality target group of people. The event marketing, Bangladesh Mathematical Olympiad, creates a unique opportunity to make a face-to-face interaction between the companies and the customers or clients at the special event. This practice ensures consumer engagement and creates opportunities to have opinions and feedbacks from customers for further improvement.

Moreover, this initiative has introduced a joyful Mathematics practice all over the country. Actually, it plays a vital role in making Prothom Alo the most influential brand in Bangladesh. Math Olympiad is supporting in marketing through reputation building, loyal customer building, higher recall value, word of mouth marketing, healthy competition, and higher sales value.

After the immense success of this event, a solid base of the business relationship has created between Prothom Alo and Dutch-Bangla Bank Limited. Dutch-Bangla Bank shows interest to sponsor other programs of Prothom Alo. Additionally, Dutch-Bangla Bank inserts more advertisements in Prothom Alo than before.

On the other hand, an event marketing is truly time consuming and expensive. Planning, budget making, 
sponsoring, logistics, mailing, advertising, venue confirmation, catering, volunteer management, media coverage, guest management, and academic support require a huge budget and managerial expertise. Gathering the right target group of people with proper demography is always a big challenge.

\section{Conclusion}

Considering marketing and people's expediency purpose, Bangladesh Mathematical Olympiad is a very successful event. Participants of Bangladesh Mathematics Olympiad dream that if they can do well in this competition, then they will have many opportunities for them in the future. They now learn Math in happiness and self-interest. With this long journey of the event, Prothom Alo and Dutch-Bangla Bank have made a strong relationship with the customers .An event like Bangladesh Mathematical Olympiad is always an ideal model for any successful event marketing.

Future research scope

Not only the event marketing like Mathematical Olympiad but also other factors like brand name, product or service quality, store design etc. can enhance positive brand image.

\section{References}

i) Cooil, B., Keiningham, T., Aksoy, L. and Hsu, M. (2007), "Alongitudinal analysis of customer satisfaction and share of wallet: investigating the moderating effect of customer characteristics", Journal of Marketing, Vol. 71, January, pp. 67-83

ii) Gould, G., 1995. "Why it is customer loyalty that counts (and how to measure it)." Managing Service Quality 5 (1), 15-19.

iii) Gronroos. C.(2007) “ Service Management and Marketing- Customer Management in Service Competition " 3 rd edition, John Wiley \& Sons, Ltd

iv) Kotler, P. \& Armstrong, G. (2008). Principles of Marketing. 12th Edition. Harlow: Financial Times Prentice Hall.

v) Paulin M., Ferguson R .J. \& Marielle Payaud (2000), "Effectiveness of Relational and Transactional cultures in commercial banking: putting client-value into the competing values model", International Journal of Bank Marketing.

vi) Reichheld, F. F. (2001), "Lead for loyalty”, Harvard Business Review, 2001 Jul-Aug; 79(7):76-84, 144. Bain \& Company, Boston, USA.

vii) Sirdeshmukh, D., Singh, J. and Sabol, B. (2002), "Consumer trust, value, and loyalty in relational exchanges", Journal of Marketing, Vol. 66, pp. 15-37

viii) Tohidinia, Z. \& Haghighi, M. (2011), "Predictors and outcomes of relationship quality: a guide for customer-oriented strategies", Business Strategy Series, Vol.12 No. 5, pp. 242-256.

ix) Yang, Z. \& Peterson, R. T (2004), "Customer Perceived Value, Satisfaction, and Loyalty: The Role of Switching Costs, Psychology \& Marketing," Vol. 21(10):799-822

x) Zeithaml, V. and Bitner, M. J. (2003), Services Marketing, 3rd Edition, McGraw-Hill. 